\title{
Acute-Phase Proteins and Chlamydia pneumoniae Infection Which One is More Important in Acute Coronary Syndrome?
}

\author{
Hongmei Song, MD; Hiromi Tasaki, MD; Akira Yashiro, MD; \\ Kazuhito Yamashita, MD; Hatsumi Taniguchi, MD*; Yasuhide Nakashima, MD
}

\begin{abstract}
Elevated levels of acute-phase proteins, a systemic marker for inflammation, predict coronary events; Chlamydia pneumoniae (C. pneumoniae) infection is associated with coronary atherosclerosis. The present study investigated whether inflammation or infection is involved in the pathogenesis of acute coronary syndrome (ACS) and which one has the more important role. The study group comprised 49 patients with angiographically diagnosed ACS, 48 cases of chronic coronary heart disease (CCHD), and 44 subjects with a normal coronary profile. The levels of serum C-reactive protein (CRP), fibrinogen and anti-C. pneumoniae $\operatorname{IgG}$ antibody were measured. The IgG antibody against $\mathrm{C}$. pneumoniae was higher in the ACS and CCHD groups compared with the control group after adjusting for age and gender. The levels of CRP and fibrinogen were significantly increased in patients with ACS compared with controls and CCHD patients. Multiple stepwise logistic regression analysis revealed that C. pneumoniae IgG antibody is an independent risk factor for both ACS and CCHD (odds ratio 2.3 and 2.1, respectively), but the CRP level is a risk factor only for ACS (odds ratio 6.9). The inflammatory response, as indicated by acute-phase proteins, especially CRP, rather than C. pneumoniae infection, may contribute more to the clinical course of ACS. (Jpn Circ J 2001; 65: 853-857)
\end{abstract}

Key Words: Acute coronary syndrome; Acute-phase proteins; Chlamydia pneumoniae; Chronic coronary heart diseases; Inflammation

I is generally accepted that acute coronary syndrome (ACS) is the result of persistent instability and abrupt changes in the atherosclerotic plaque that lead to local thrombus formation, ${ }^{1,2}$ but the underlying pathogenetic mechanisms have not been fully elucidated. Experimental and clinical studies, based on the markers of inflammation and inflammatory mediators in plasma as well as in samples of atherosclerotic tissues, have provided ample evidence for the presence of ongoing inflammation in atherosclerosis $3^{3-5}$ Inflammation may contribute to weakening of the atherosclerotic plaque and could play a crucial role in the rupture of the fibrous cap, with subsequent exposure of the lipid-core to circulating blood components, resulting in the coronary thrombosis that is the main cause of the ACS of unstable angina, myocardial infarction, and sudden coronary death6 Elevated levels of C-reactive protein (CRP), a major inflammatory marker, have been found in individuals with ACS7-10 and an elevated level of fibrinogen, a readily measurable acute-phase protein, at the time of hospital admission is associated with coronary ischemic events and a poor clinical outcome in patients with unstable angina!1 On the other hand, several studies have reported that systemic or local infections are associated with $\mathrm{ACS}, 12,13$ and thus far, the strongest association appears to be with Chlamydia pneumoniae (C. pneumoniae)

(Received January 11, 2001; revised manuscript received June 26, 2001; accepted July 5, 2001)

Second Department of Internal Medicine and *Department of Microbiology, University of Occupational and Environmental Health, School of Medicine, Kitakyushu, Japan

Mailing address: Hiromi Tasaki, MD, PhD, 2nd Dept of Internal Medicine, University of Occupational and Environmental Health, School of Medicine, 1-1 Iseigaoka, Yahatanishiku, Kitakyushu 8078555, Japan. E-mail: h-tasaki@med.uoeh-u.ac.jp and the most significant association in most studies appears to be with coronary atherosclerosis ${ }^{14}$ Seroepidemiologic data, isolation of C. pneumoniae from the atheroma plaque, experimental evidence, and the results of early antibiotic trials directed against $\mathrm{C}$. pneumoniae together suggest that C. pneumoniae infection is a strong risk factor for the development of atherosclerosis ${ }^{15,16}$ However, the role of C. pneumoniae in atherosclerosis is still controversial because of some negative data ${ }^{17}$ and it is still not known whether this infection has the same effect in the pathogenesis of ACS and of chronic coronary heart disease (CCHD).

The relevance of these factors to the causation of atherosclerosis, however, remains uncertain. An elevated level of CRP may merely reflect the extent and severity of the atheroma, of which inflammation is an essential component. Alternatively, altered levels of these factors may be induced by low-grade inflammation or infection elsewhere in the body that could be relevant to the causation of atherosclerosis. Another possibility is that the altered plasma protein profile during tissue damage, or the specific actions of particular acute-phase proteins, or both, might increase the incidence of atherosclerosis ${ }^{18}$ To investigate issue, we measured acute-phase proteins, such as serum CRP, fibrinogen and $\operatorname{IgG}$ specific antibody against C. pneumoniae, in patients with angiographically determined ACS and CCHD. Furthermore we investigated whether inflammation and infection are both involved in the pathogenesis of $\mathrm{ACS}$, and which one is more important.

\section{Methods}

\section{Patients}

We enrolled 49 patients with angiographically diagnosed ACS, of which 19 had unstable angina and 30 had acute 
Table 1 Clinical Characteristics of the Study Population

\begin{tabular}{lccc}
\hline \hline & $\begin{array}{c}\text { Control } \\
(n=44)\end{array}$ & $\begin{array}{c}\text { ACS group } \\
(n=49)\end{array}$ & $\begin{array}{c}\text { CCHD group } \\
(n=48)\end{array}$ \\
\hline Age (years) & $58.0 \pm 12.4$ & $58.6 \pm 10.2$ & $60.5 \pm 11.8$ \\
Male/female & $22 / 22$ & $35 / 14^{*}$ & $36 / 12^{*}$ \\
Obesity (yes/no) & $21 / 23$ & $32 / 17$ & $32 / 16$ \\
BMI $\left(\mathrm{kg} / \mathrm{m}^{2}\right)$ & $23.5 \pm 3.4$ & $24.0 \pm 3.1$ & $24.4 \pm 3.2$ \\
Smoking (yes/no) & $18 / 26$ & $35 / 14^{*}$ & $28 / 20$ \\
Hypertension (yes/no) & $20 / 24$ & $25 / 24$ & $24 / 24$ \\
Diabetes mellitus (yes/no) & $4 / 40$ & $9 / 40$ & $12 / 36^{*}$ \\
Hypercholesterolemia (yes/no) & $12 / 32$ & $22 / 27$ & $28 / 20^{* *}$
\end{tabular}

Data are means \pm standard deviation (SD) or number of patients. ACS, acute coronary syndrome; BMI, body-mass index; CCHD, chronic coronary heart disease. Differences were examined using ANOVA and the Scheffe's multiple comparison among groups for continuous variables, and the chi-square test for categorical variables. ${ }^{*} p<0.05, * * p<0.01$ compared with control.

myocardial infarction (AMI). The diagnosis of unstable angina was based on the following inclusion criteria: angina at rest with more than 2 ischemic episodes or 1 episode lasting more than $20 \mathrm{~min}$ in the past $24 \mathrm{~h}$ with diagnostic ST-segment changes ${ }^{19}$ The diagnosis of AMI was based on at least 2 of the following criteria: (1) recent onset
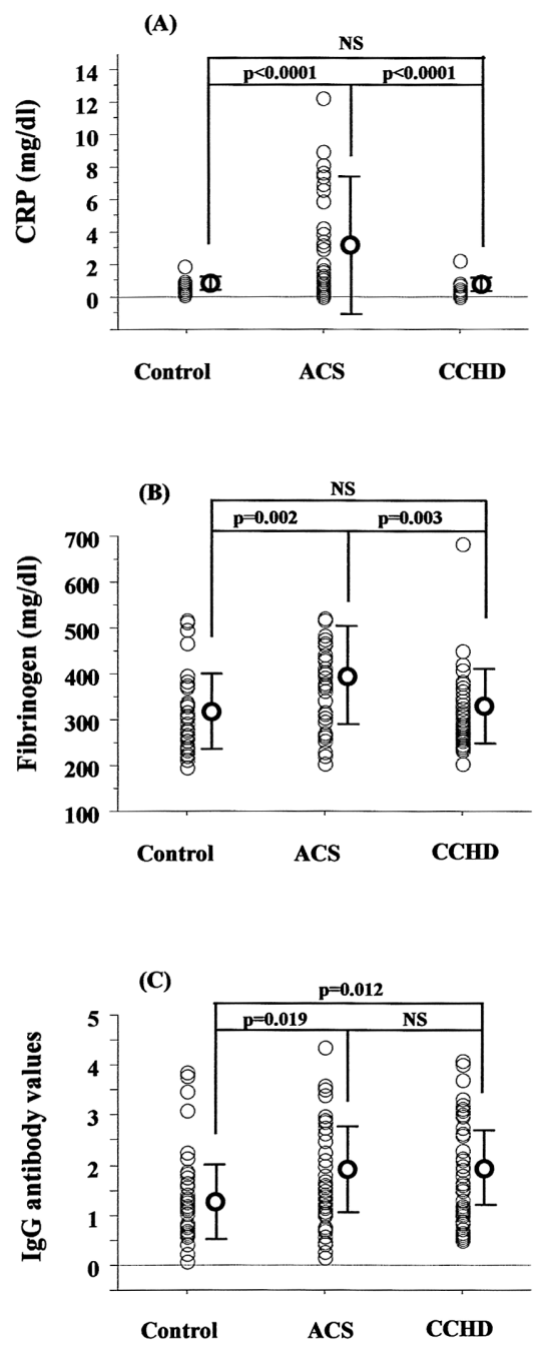

Fig 1. Concentrations $(\mathrm{mg} / \mathrm{dl})$ of serum $\mathrm{C}$-reactive protein $(\mathrm{CRP})$ (A), fibrinogen (B) and IgG antibody against C. pneumoniae (C) in different groups. NS, not significant; other abbreviations as defined in Table 1. of symptoms $(<6 \mathrm{~h})$ characterized by typical chest pain lasting more than $20 \mathrm{~min}$ and resistant to nitrates; (2) typical changes in the electrocardiogram; and (3) raised serum enzyme levels?,10 Patients were excluded according to the following criteria: malignancy or inflammatory disease, surgery or major trauma in the previous month, known thrombotic disorders, dilated cardiomyopathy, previous myocardial infarction within the past 3 weeks to 3 months, ejection fraction less than $40 \%$ or age greater than 75 years, because these conditions carry an additional risk independent of the severity of instability 19 Forty-four patients with no demonstrable lesions and 48 patients with significant stenosis on coronary angiograms served as the controls and CCHD group, respectively. The prevalence of hypertension, hypercholesterolemia and diabetes were assessed according to the medical history. The body-mass index (BMI) was calculated by the standard formula (weight in $\mathrm{kg} / \mathrm{height}$ in $\mathrm{m}^{2}$ ). All patients were taking various combinations of intravenous or oral nitrates, $\beta$-blockers, aspirin, heparin and calcium antagonists.

\section{Coronary Angiography}

Coronary angiography was performed by the Judkins' technique in each patient using a HICOR System. Significant stenosis was defined as at least one major coronary artery lesion occupying more than $75 \%$ in diameter according to the criteria of the American Heart Association (AHA). Normal segments were defined as those without any wall irregularities. Patients who had undergone percutaneous transluminal coronary angioplasty or coronary artery bypass surgery at admission were excluded.

\section{Assays}

Venous blood samples were obtained at the time of hospital admission for all patients. Serum level of CRP was measured using a latex agglutination immunoassay (SRL, Inc, Japan). Plasma fibrinogen concentration was detected with a kit using a thrombin coagulation time method (SRL, Inc). Other biochemical parameters were determined by routine procedures.

The serum level of anti-C. pneumoniae specific IgG antibody was measured with a new enzyme-linked immunosorbent assay (ELISA) method using C. pneumoniae specific outer membrane complex protein as an antigen (Hitachi Chemical Co, Ltd, Tokyo) because ELISA has been found to be more sensitive and specific than immunofluorescence for detecting antibodies to C. pneumoniae?20 Briefly, specimens were diluted 210-fold, added to the antigen-coated microtiterplates and then reacted sequentially with the 
Table 2 Odds Ratio With 95\% Confidence Intervals (CI) for ACS and CCHD With Different Risk Factors

\begin{tabular}{|c|c|c|c|c|}
\hline \multirow[t]{2}{*}{ Risk factors } & \multicolumn{2}{|c|}{$\begin{array}{c}\text { ACS group }(n=49) \\
\text { against control }(n=44)\end{array}$} & \multicolumn{2}{|c|}{$\begin{array}{l}\text { CCHD group }(n=48) \\
\text { against control }(n=44)\end{array}$} \\
\hline & Odds ratio & $95 \% C I$ & Odds ratio & $95 \% C I$ \\
\hline Diabetes mellitus & - & - & 11.9 & $2.2-63.6$ \\
\hline Hypercholesterolemia & 6.0 & $1.5-23.8$ & 7.6 & $2.4-24.3$ \\
\hline Serum CRP & 6.9 & $1.8-26.3$ & - & - \\
\hline C. pneumoniae $\operatorname{Ig} G$ value & 2.3 & $1.1-4.6$ & 2.1 & $1.2-3.8$ \\
\hline
\end{tabular}

Odds ratios with $95 \%$ CI for ACS and CCHD were determined by stepwise logistic regression analysis adjusted for age and gender. Abbreviations as in Table 1 and Fig 1.

second antibody labeled with alkaline phosphatase, substrate ( $\mathrm{O}$-nitrophenyl phosphate), and stop solution $(3 \mathrm{~mol} / \mathrm{L}$ $\mathrm{NaOH})$. The optical density was measured at $405 \mathrm{~nm}$, and the cut-off values were calculated as described by the manufacturer.

\section{Statistical Analysis}

Values are expressed as means \pm standard deviation (SD). Data were analyzed using the Statistical Analysis System (SAS) software package (Version 6.12; SAS Institute Inc, Cary, NC, USA). Differences were determined using ANOVA and the Scheffe's multiple comparison for continuous variables, and the chi-square test for categorical variables among the groups. Stepwise logistic regression analysis was performed to determine the independent relationships for risk factors to ACS or CCHD against control, presented by the odds ratios (OR) and 95\% confidence intervals $(95 \% \mathrm{CI})$. In this model, major conventional risk factors (smoking, hypertension, diabetes mellitus and hypercholesterolemia), serum CRP, and IgG antibody value against $C$. pneumoniae were used as independent variables. Pearson's correlation coefficients were analyzed to examine the association among continuous parameters. Statistical significance was established at the $\mathrm{p}<0.05$ level.

\section{Results}

The clinical characteristics of the 44 controls, 49 ACS and 48 CCHD patients are summarized in Table 1. Patients with ACS and CCHD were more frequently male than the control subjects. The ACS and CCHD groups were very similar in other conventional risk factors for coronary atherosclerosis, although there were some differences between either the ACS or CCHD group and the control group in the prevalence of smoking, diabetes and hyperlipidemia.

The biochemical variables measured in the study population are shown in Fig 1. The levels of acute-phase proteins (ie, CRP: $2.4 \pm 3.1 \mathrm{mg} / \mathrm{dl}$; fibrinogen: $383.3 \pm 107.4 \mathrm{mg} / \mathrm{dl}$ ) in patients with ACS were significantly higher compared with controls $(0.2 \pm 0.3 \mathrm{mg} / \mathrm{dl}$ and $311.1 \pm 84.5 \mathrm{mg} / \mathrm{dl} ; \mathrm{p}<0.001$ and $\mathrm{p}=0.002$, respectively), and with CCHD cases $(0.2 \pm 0.4$ $\mathrm{mg} / \mathrm{dl}$ and $318.7 \pm 81.9 \mathrm{mg} / \mathrm{dl}, \mathrm{p}<0.001$ and $\mathrm{p}=0.003$, respectively).

After adjusting for age and gender, the IgG antibody value against $\mathrm{C}$. pneumoniae was significantly higher in patients with ACS $(1.74 \pm 1.01)$ and CCHD $(1.77 \pm 0.99)$ as compared with the control group $(1.27 \pm 0.88, \mathrm{p}=0.019$ and 0.12 , respectively, Fig $1 \mathrm{C}$ ), but there was no significant difference between the ACS and CCHD groups.

Multiple stepwise logistic regression analysis (Table 2) revealed that hypercholesterolemia, elevated serum CRP level and C. pneumoniae IgG antibody value are independent risk factors for ACS. The risk factors for CCHD are diabetes, hypercholesterolemia, and a high $\mathrm{C}$. pneumoniae IgG antibody value, but not serum CRP level.

Of the correlations among the continuous parameters in the ACS group (Fig 2), the levels of serum CRP and fibrinogen were associated with each other, but we did not detect any relation between $C$. pneumoniae $\operatorname{IgG}$ antibody and increased acute-phase proteins. Moreover, we did not
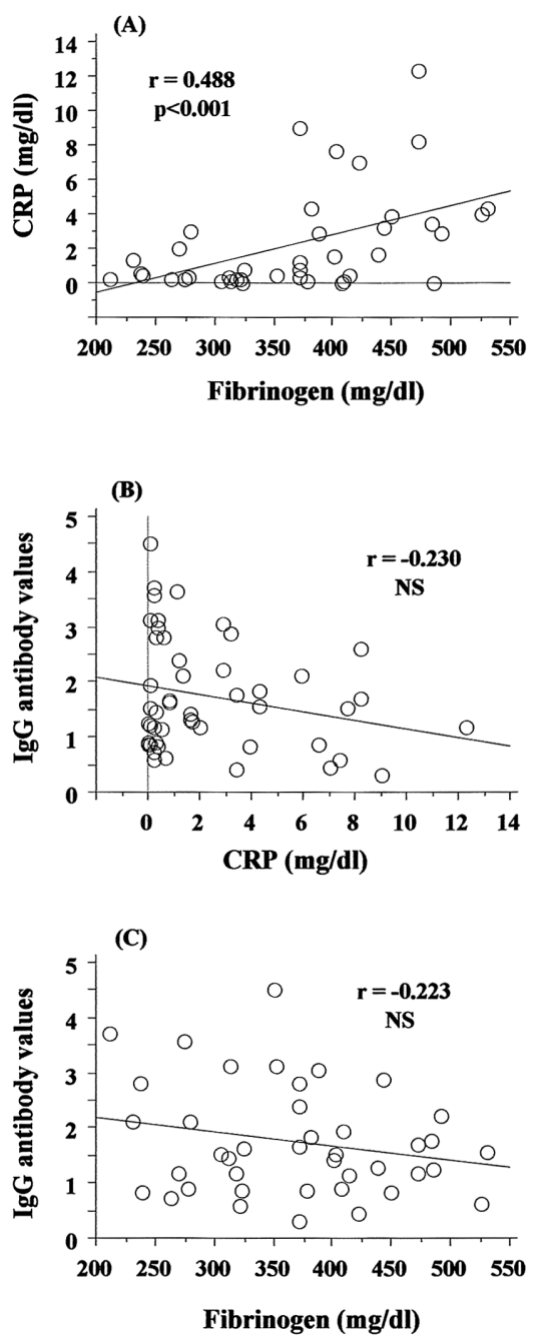

Fig 2. Association among serum CRP, fibrinogen and $\operatorname{IgG}$ antibody in the acute conronary syndrome (ACS) group. Pearson's correlation coefficients (r) were analyzed to determine the relationships. Abbreviations as defined in Fig 1. 
find a significant association between the degree of coronary atherosclerosis and the levels of C. pneumoniae $\mathrm{IgG}$ antibody or inflammatory markers in either the ACS or CCHD group (data not shown).

\section{Discussion}

Saikku et al first reported the serological association of C. pneumoniae infection with AMI and chronic coronary heart disease ${ }^{21}$ and after that, others ${ }^{22,23}$ have studied this association and demonstrated the presence of the organism within atherosclerotic lesions by polymerase chain reaction (PCR), immunocytochemistry and electron microscopy? 24 In fact, C. pneumoniae has been successfully isolated from atherosclerotic lesions ${ }^{25}$ and, based on the laboratory and clinical evidence, pilot trials of macrolide antibiotics in both patients with coronary heart disease ${ }^{26}$ and in an animal model $^{27}$ were performed.

However, there are other conflicting results. Some serological studies do not support an association between $\mathrm{C}$. pneumoniae and coronary atherosclerosis 28 and a pathological investigation failed to demonstrate C. pneumoniae in atherosclerotic plaques! ${ }^{17}$ Although our data provided a positive serological association between C. pneumoniae infection and coronary atherosclerosis both in ACS and CCHD patients, in accordance with other previously reported results, C. pneumoniae serology may be less specifically predictive for ACS.

It is apparent from the histological and biochemical evidence that an intravascular inflammatory response is an integral component of plaque instability. Previous studies have found elevated values of acute-phase proteins in patients with unstable angina and $\mathrm{AMI} 29$ which is supported by our present findings that the levels of CRP and fibrinogen were increased and that of serum albumin was decreased significantly in the patients with ACS, and that serum CRP was an independent predictor strongly related only to ACS, not to CCHD. Although these results may merely reflect the underlying biological processes triggered by plaque rupture, a causal role cannot be excluded because they may also reflect a pro-inflammatory state with possibly negative effects on the healing processes within the unstable plaque. Thus when a plaque ruptures, this proinflammatory state may enhance the processes leading to persistent instability 30 Our finding of a close association between CRP and fibrinogen further supports the likelihood of some underlying processes related to the inflammation that occurs in ACS.

$\mathrm{CRP}$, as a marker for systemic inflammation, is reliably assayed and has been consistently found to be elevated in patients with coronary syndrome, and has also been found to predict future events 29 Furthermore, there is some evidence that CRP not only serves as a marker of the acute phase response, but is also involved in the pathogenesis of the disease. CRP stimulates the production of tissue factor, the main initiator of blood coagulation, by mononuclear cells, ${ }^{31}$ and this may contribute to instability of the plaque and the subsequent clinical course. After AMI, CRP may become a cardiovascular risk factor because it localizes in ischemic myocardium and atherosclerotic lesions, thereby promoting local complement activation. ${ }^{2}$ Fibrinogen is a major determinant in the generation of fibrin-platelet plugs and thrombus formation, suggesting a causative association with coronary thrombosis 33 The mechanism by which fibrinogen influences the onset and development of atherosclerotic heart disease is not fully understood. It may contribute to plaque growth and the risk of thrombosis by increasing plasma viscosity, the aggregation of red blood cells and platelets, and by direct incorporation into the injured endothelium and promotion of regional fibrin deposition 34

No association was demonstrated in the present study between the levels of inflammatory markers and $\mathrm{C}$. pneumoniae antibody in either ACS or CCHD patients. Undoubtedly, chronic C. pneumoniae infection and its reactivation are plausible inflammatory stimuli, but many other as yet undetermined toxic factors, chronic infections or immunological factors may also be responsible for stimulating the production of pro-inflammatory mediators leading to the acute phase response and increased levels of acute-phase proteins?

In summary, the present study confirms the association of C. pneumoniae infection with angiographically documented coronary atherosclerosis in both ACS and CCHD. In addition, the inflammatory response, represented by changes in the concentrations of acute-phase proteins, especially serum CRP, is a key mechanism in the development of ACS. However, the roles of inflammation and infection as potential atherosclerosis risk factors are still unclear and more data and larger prospective studies are necessary to clarify this issue.

\section{References}

1. Fuster V, Badimon L, Badimon JJ, Chesebro JH: The pathogenesis of coronary artery disease and acute coronary syndromes: Part 1 and 2. N Engl J Med 1992; 326: 242-250, 310-318

2. Théroux P, Fuster V: Acute coronary syndromes: Unstable angina and non-Q wave myocardial infarction. Circulation 1998; 97: 11951206

3. Mehta JL, Saldeen TGP, Rand K: Interactive role of infection, inflammation and traditional risk factors in atherosclerosis and coronary artery disease. J Am Coll Cardiol 1998; 31: 1217-1225

4. Curzen N, Fox K: Inflammation and outcome in unstable angina. Eur Heart J 1999; 20: 554-555

5. Roivainen M, Viik-Kajander M, Palosuo T, Toivanen P, Leinonen $\mathrm{M}$, Saikku P, et al: Infections, inflammation, and the risk of coronary heart disease. Circulation 2000; 101: 252-257

6. Falk E, Denmark A: Stable versus unstable atherosclerosis: Clinical aspects. Am Heart J 1999; 138: s421-s425

7. Liuzzo G, Biasucci LM, Gallimore JR, Grillo RL, Rebuzzi AG, Pepys $\mathrm{MB}$, et al: The prognostic value of $\mathrm{C}$-reactive protein and serum amyloid a protein in severe unstable angina. $N$ Engl $J$ M 1994; 331: $417-424$

8. Ferreirós ER, Boissonnet CP, Pizarro R, Merletti PF, Corrado G, Cagide A, et al: Independent prognostic value of elevated C-reactive protein in unstable angina. Circulation 1999; 100: $1958-1963$

9. Liuzzo G, Biasucci LM, Gallimore JR, Caligiuri G, Buffon A, Rebuzzi AG, et al: Enhanced inflammatory response in patients with preinfarction unstable angina. J Am Coll Cardiol 1999; 34: 16961703

10. Kosuge M, Kimura K, Ishikawa T, Endo T, Shigemasa T, Okuda J, et al: Relation between C-reactive protein levels on admission and pattern of acute myocardial infarction onset. Am J Cardiol 2000; 86: $83-86$

11. Becker RC, Cannon CP, Bovill EG, Tracy RP, Thompson B, Knatterud GL, et al: Prognostic value of plasma fibrinogen concentration in patients with unstable angina and non-Q-wave myocardial infarction (TIMI IIIB trial). Am J Cardiol 1996; 78: 142-147

12. Saikku P: Chlamydia pneumoniae infection as a risk factor in acute myocardial infarction. Eur Heart J 1993; 14(Suppl K): 62-65

13. Valtonen V: Role of infections in atherosclerosis. Am Heart J 1999; 138: $s 431-s 433$

14. Leinonen M, Saikku P: Infections and atherosclerosis. Scand Cardiovasc J 2000; 34: 12-20

15. Molt C: Chlamydia linked to atherosclerosis. Science 1996; 272: 1422

16. Capron L: Chlamydia in coronary plaques: Hidden culprit or harmless hobo? Nat Med 1996; 2: 856-857 
17. Cellesi C, Sansoni A, Casini S, Migliorini L, Zacchini F, Gasparini $\mathrm{R}$, et al: Chlamydia pneumoniae antibodies and angiographically demonstrated coronary artery disease in a sample population from Italy. Atherosclerosis 1999; 145: 81-85

18. Danesh J, Muri J, Wong YK, Ward M, Gallimore JR, Pepys MB: Risk factors for coronary heart disease and acute-phase proteins: A population-based study. Eur Heart J 1999; 20: 954-959

19. Biasucci LM, Liuzzo G, Grillo RL, Caligiuri G, Rebuzzi AG, Buffon $\mathrm{A}$, et al: Elevated level of C-reactive protein at discharge in patients with unstable angina predict recurrent instability. Circulation 1999; 99: $855-860$

20. Numazaki K, Ikebe T, Chiba S: Detection of serum antibodies against Chlamydia pneumoniae by ELISA. FEMS Immunol Med Microbiol 1996; 14: 179-183

21. Saikku P, Leinonen M, Mattila K, Ekman MR, Nieminen MS, Makela PH, et al: Serological evidence of an association of a novel Chlamydia, TWAR, with chronic coronary heart disease and acute myocardial infarction. Lancet 1988; 2: 983-986

22. Kosada C, Hara K, Komiyama Y, Takahashi H: Possible role of chronic infection with Chlamydia pneumoniae in Japanese patients with acute myocardial infarction. Jpn Circ J 2000; 64: 819-824

23. Shimada K, Daida H, Mokuno H, Watanabe Y, Sawano M, Iwama Y, et al: Association of seropositivity for antibody to Chlamydiaspecific lipopolysaccharide and coronary artery disease in Japanese men. Jpn Circ J 2000; 65: 182-187

24. Davidson M, Kuo CC, Middaugh JP, Campbell LA, Wang SP, Newman WP $3^{\text {rd }}$, et al: Confirmed previous infection with Chlamydia pneumoniae (TWAR) and its presence in early coronary atherosclerosis. Circulation 1998; 98: 628-633

25. Ramirez JA, the Chlamydia pneumoniae/Atherosclerosis Study Group: Isolation of Chlamydia pneumoniae from the coronary artery of a patient with coronary atherosclerosis. Ann Intern Med 1996;
125: $979-982$

26. Anderson JL, Muhlestein JB, Carlquist J, Allent A, Trehan S, Nielson $\mathrm{C}$, et al: Randomized secondary prevention trial of azithromycin in patients with coronary artery disease and serological evidence for Chlamydia pneumoniae infection. Circulation 1999; 99: 1540-1547

27. Muhlestein JB, Anderson JL, Hammond EH, Zhao L, Trehan S, Schwobe EP, et al: Infection with Chlamydia pneumoniae accelerates the development of atherosclerosis and treatment with azithromycin prevents it in a rabbit model. Circulation 1998; 97: 633-636

28. Nieto FJ, Folsom AR, Sorlie PD, Grayston JT, Wang SP, Chambless LE, et al: Chlamydia pneumoniae infection and incident coronary heart disease. The atherosclerosis risk in communities study. Am J Epidemiol 1999; 150: 149-156

29. Abdelmouttaleb I, Danchin N, Ilardo C, Aimone-Gastin I, Angioi M, Lozniewski A, et al: C-reactive protein and coronary artery disease: Additional evidence of the implication of an inflammatory process in acute coronary syndromes. Am Heart J 1999; 137: 346-351

30. Verheggen PWHM, de Maat MP, Cats VM, Haverkate F, Zwinderman $\mathrm{AH}$, Kluft $\mathrm{C}$, et al: Inflammatory status as a main determinant of outcome in patients with unstable angina, independent of coagulation activation and endothelial cell function. Eur Heart J 1999; 20: $567-$ 574

31. Cermak J, Key NS, Bach RR, Balla J, Jacob HS, Vercellotti GM: Creactive protein induced tissue factor. Blood 1993; 82: 513-520

32. Lagrand WK, Visser CA, Hermens WT, Niessen HW, Verheugt FW, Wolbink GJ, et al: C-reactive protein as a cardiovascular risk factor more than an epiphenomenon? Circulation 1999; 100: 96-102

33. Meade TW: Fibrinogen in ischemic heart disease. Eur Heart J 1995; 16(Suppl A): $31-35$

34. Irish A: Cardiovascular disease, fibrinogen and the acute phase response associations with lipids and blood pressure in patients with chronic renal disease. Atherosclerosis 1998; 137: 133-139 